\title{
The Role of Engagement on the Relationship Between Motivation and Future Volunteering Intention: The Case of the 30th Southeast Asian Games
}

\author{
Roel S. Agustin \\ Holy Angel University, School of Hospitality and Tourism Management, Philippines
}

\begin{abstract}
Volunteering in major sporting events has become a trend, for sports volunteers are considered one of the most valuable human resources to the event. This study intended to establish a structural model that describes the role of engagement on the relationship between motivation and future volunteering intention in a sporting event. It aimed to provide implications for organizers and volunteer coordinators to effectively retain experienced volunteers and motivate them to engage in future events. The participants of the study were the 168 sport event volunteers at the 30th SEA Games - Clark Cluster. The data were analyzed using Structural Equation Modeling to test the causal relationships of the variables. The study found that skill enrichment, privileges of volunteering, and social enrichment positively influenced volunteer engagement, while community contribution, skill enrichment, positive life experiences, and volunteer engagement positively influenced intention to volunteer in the future. The study concluded that volunteer engagement has no mediating role between motivation and future volunteering intention. Sport event organizers must manage volunteers by satisfying their personal and social needs toward volunteering and providing moral support through proper work design, efficient training, and an inclusive working environment to keep them engaged and committed in sustaining their volunteering act.
\end{abstract}

Keywords: sports event volunteering; volunteer motivation; volunteer engagement; future volunteering intention; sporting event volunteer management; 30th SEA Games

This is an open access article under the CC-BY-NC license.

\section{INTRODUCTION}

Major sporting events are proven to bring significant social benefits, national pride and are considered as one of the largest revenue sources in the events industry, providing considerable economic benefits to the host country in general. The Olympic Games, which is being held every four years, is known as the hallmark of all sporting events, bringing more than six million tourists to its host city (Walker \& Walker, 2012). Based on the report published by the International Olympic Committee in 2020, the last two Olympic Games in the past six years, including Winter Olympic Games 2014 in Sochi, Russia and the Summer Olympic Games 2016 in Rio de Janeiro, Brazil, generated a total of 5.7 billion USD revenue. Meanwhile, in the Southeast Asian Region, Malaysia and the Philippines hosted the last two editions of the Southeast Asian Games (SEA Games) in 2017 and 2019, respectively, have recorded a significant increase in their tourism receipts, which translated into financial growth in their respective national economies. In 2017, Malaysia received 25.95 million international tourists, which translated to 82.1 Billion RM (around 20 Billion USD) (Tourism Malaysia, 2020), while the Philippines received the all-time high of 8.26

Corresponding author

Roel S. Agustin, ragustin.files@gmail.com

DOI: (to be assigned soon)

Research Synergy Foundation 
million international tourist arrivals, which translated to 482.15 Billion PHP (around 9.31 Billion USD) and was $20.81 \%$ higher than 2018 (DOT, 2020), where a large portion of the total amount gained is related to the hosting of the SEA Games. Social benefits are also associated with the hosting of such major international sports events. The community benefits from the significant investment in the improvement of infrastructures vital in the conduct of the event (Pettinger, 2019). These long-term investments serve as a legacy to the host city or country, such as modern sporting venues including stadiums, training facilities, athlete's village, etc., improved public transportation through the construction of roads, bridges and highways, which the locals can also use during and after the games. Hosting a major international sporting event promotes a sense of national or community pride among the locals (Leng \& Hopfl, 2013; Storm \& Jakobsen, 2019). Holding a prestigious event such as sport which draws interest from many people, enhances the image of the host community and elevates its value in the society, which leaves a good lasting impression. In addition, conducting a major sporting event can generate excitement and enthusiasm among the stakeholders and can lead to the emergence of social responsibility and volunteerism (Pettinger, 2019).

All of these tangible and intangible benefits of major sporting events would not be realized without the massive support of sports volunteers. Sport event volunteers are regarded as one of the most valuable and vital human resources to the sporting event, and in many cases, the sports industry depends on volunteers (Mirsafian et al., 2011; Mostahfezian et al., 2012; Bang, 2007; Khairullina, 2014; Goldblatt, 2008). Several studies have recognized the roles of volunteers in many sporting events regardless of size. Organizers recruit a large number of volunteers to assist all the stakeholders in the event by serving in different functional areas such as administration, information technology, medical services, food and beverage, ceremonies, ticketing, etc. As for mega-events such as the Olympic Games, it typically requires enormous numbers of sport event volunteers.

There were several studies conducted relating to motivational factors that the volunteers consider in participating in such volunteering acts in different sectors such as charitable organizations, environmental conservation, civic movement, religious and educational institutions and many more. However, one of the most interesting sectors that stimulate interest in volunteerism is special events - that is, major sporting events. Similarly, a number of researches have been conducted proving the significant relationship between sport event volunteers' motivation and satisfaction and volunteer sustainability and retention, hence, this present study aims to investigate the role of volunteer engagement, as a mediating factor, in the relationship between volunteer motivation and future volunteering intention. This study correlates the level of volunteer motivation that leads to intention to volunteer in the future through significant level of volunteer engagement. This study aims to contribute to the collection of literatures on studying volunteerism in major sporting event particularly in Southeast Asian region since there were limited studies conducted with similar construct. Moreover, this study provides vital information about volunteers' motivation and engagement as they influence their future volunteering intention, thus, having implications for event management to sustain the spirit of volunteerism. 
Journal of Social Entrepreneurship Theory and Practice (JSETP), Vol. 1 (1), 28-50

The Role of Engagement on the Relationship Between Motivation and Future Volunteering Intention: The

Case of the 30th Southeast Asian Games

Roel S. Agustin

\section{The Southeast Asian Games}

The Southeast Asian Games or popularly known as SEA Games is a biennial sporting event participated by eleven member countries of the SEA Games Federation, including Thailand, Myanmar, Kuala Lumpur, Indonesia, Philippines, Singapore, Brunei, Vietnam, Laos, Cambodia and East Timor with the aim of enhancing relations and promoting cooperation among these membercountries. The SEA Games history can be traced to the original sporting event called Southeast Asia Peninsular Games or SEAP Games spearheaded by Luang Sukhum Nayapradit of Thailand and later on became the chairman of the association. The associations started admitting other countries in the region since 1977, which marked the start of the SEA Games (SEA Games Federation, 2020; Tatler Philippines, 2019). All of the member countries have hosted the Games except for East Timor, which debuted only in 2003. In 2019, the Philippines was entrusted to host its 30th edition for the fourth time with the theme "We Win as One," the Philippines first hosted the SEA Games in 1981, followed in 1991 and then in 2005. The Philippines 2019 edition was considered as the biggest SEA Games in history in terms of the number of sporting events with a total of 530 events in 56 sports (10 of which debuted during the Games, including e-sports) participated by 10,960 athletes and officials with the Philippines having the largest contingent of 1,847 athletes and officials and played in 4 clustered venues in Luzon island including Clark, Subic, Metro Manila and "other areas" (Batangas, Cavite, Laguna and La Union) organized by 527 event workforce and assisted by 9,000 local and foreign volunteers (Morales, 2019; Manalili, 2019; DOH 2019; PHISGOC, 2019).

\section{LITERATURE REVIEW}

Volunteering is becoming more popular nowadays. Volunteering is defined as offering free assistance through organizations and community to help people or benefit the environment, committing one's time and energy and is undertaken by choice and freely; hence, volunteers are unpaid, attend training, offer effort, and often sacrifice their quality time to fulfill their duties as volunteers (Low et al., 2009, UK Volunteering Forum as cited by Rochester et al., 2010)

In two separate studies, Veludo de Oliveira, Pallister and Foxall (2015) and Solberg (2008) posited that because of altruism, empathy, beliefs, and leadership, people become involved in volunteer works. Volunteering also stimulates social values, a sense of commitment and belongingness, community development and facilitates maturity for the youth (Mostafezian et al., 2012). The University of the People (2020) identified several benefits of volunteering; these include connecting with others by meeting other people and making new friends, which improve one's social skills, second, volunteering makes people energized and feel happy at the same time because having contact with others can relieve stress while doing volunteer works, third, acquisition of skills which is possible by participating in volunteering programs and on the other hand one can also apply his own personal skills when volunteering such as communication and customer service to name a few, lastly, volunteering gives enjoyment especially on volunteer works close to one's interest or hobby such as sports.

The reason why someone is driven to perform such a thing is because of motivation. Thus, this is the reason why people submit themselves to get involved in volunteering activities. To understand a person's behavioral intention to volunteer, one must satisfy that person's motivational considerations in participating in volunteer work (Park \& Yoon, 2009 as cited by Vetitnev et al., 2019). According to Kim et al. (2020), well-managed volunteers results in effective 
volunteer performance. Thus, understanding individual volunteer's motives toward volunteering are essential information for sport event organizers to attract and retain volunteers in the future, which is the main point of the social exchange theory. Social exchange theory states that people involve themselves and uphold exchange relationships with the hope that doing so is rewarding. Further, both parties have something of value that they want and decide what to exchange (Miles, 2012). In sports events, organizers recruit and train volunteers to carry out activities necessary to stage the event successfully. On the other hand, volunteers submit themselves to offer their services not only for altruistic and philanthropic motives but with their intrinsic and extrinsic motives, including social enrichment, positive life experience, privileges of volunteering, connection with the sport, skill enrichment, and community contribution which are the main bases of the volunteer motivation variable.

Nowadays, most people are preoccupied with their individual concerns in life, such as careers and studies; however, giving back to the community is something that one should consider making time for. One of the many ways of helping the community is through volunteering. Involving oneself in volunteering activities is a fulfilling way to contribute to the community (University of the People, 2020). According to the study conducted by Bang et al. (2009), community involvement is a feeling of pride, a sense of belongingness and community spirit. Together with volunteer commitment and extrinsic rewards variables, the study also revealed that community involvement/contribution is significant in predicting future volunteering intentions. Furthermore, Graves (2019) found out that doing something worthwhile for the community results in volunteer motivation and satisfaction and makes the volunteer feel brings positive impacts to the community. In the context of this research study, community contribution is one of the motivational factors of the volunteers in joining the sport volunteering program, and community contribution variable is attributed by contributing to community spirit, helping improve the community image, putting something back into the community, helping make the sporting event a success, feeling part of the community, helping create a better society, doing something worthwhile and being involved in the sporting event.

Enrichment opportunities are one of the most important factors that motivate volunteers. According to Graves (2019), volunteers seek aspects in the volunteering program that encourage engagement and promote learning; hence, having these opportunities make volunteers more enthusiastic in the activities. As a volunteer, skill enrichment may come in two ways. First, being involved in volunteering duties provides opportunities for volunteers to acquire new skills such as technical and interpersonal. On one hand, a skilled individual who is involved in volunteering works can apply personal skills which can be improved and developed in the fulfillment of his duty. Social interaction, teamwork, organizational, communication, customer service, project planning and marketing are just a few of the many skills that a volunteer can gain and develop in participating in a sporting event volunteer program (BBBSMB, 2014). Skill enrichment is one of the motivational factors of the sports volunteers, is attributed by utilization of volunteer's personal skills, knowledge and experience and volunteer's acquisition of new skills and practical experiences.

One of the benefits of volunteering in a special event such as a major sporting event is that volunteers do something meaningful and worthwhile and at the same time having fun and enjoyment because of one's personal connection with the sport that makes this aspect of 
volunteerism special. This variable is described as "love of sport", as the volunteers' main motivation in offering their time and effort for such volunteering job. Volunteers' decision to commit and engage in volunteering activities is highly influenced by their interest in sport, and this was proven by Johnson et al. (2017) and Kim et al. (2020), where most volunteers have given higher ratings on this motive. Since sport volunteers are directly involved in the conduct of the sporting event, it is not uncommon for them to have close contact and interaction with the athletes in general and, in some cases, with elite or celebrity athletes participating in the Games.

Privileges of volunteering is one of the most evident factors motivating people to be involuntary works because of the extrinsic rewards involved. Extrinsic rewards are any tangible benefits given to a person for accomplishing something physically awarded to an individual in recognition of his participation in the unpaid work endeavor (Alumni, 2014). In the case of volunteering in a sporting event, extrinsic rewards may come in the form of souvenirs or memorabilia, complimentary tickets to the games, access to places denied to the general public, the prestige of volunteering and the opportunity to choose venue assignment. Several studies suggested that extrinsic rewards or privileges received by people as incentives from volunteering have a direct relationship with the participation, performance and engagement of the volunteer and are as important as the other motivational factors which are intrinsic in nature (Stukas et al., 2016; Mecbure \& Selen, 2020).

Developing a greater understanding and appreciation of sports, accomplishing something varied from one's regular activities, and broadening one's horizon are positive life experiences that a sport event volunteer may come across in engaging volunteering. These factors are intangible in nature as a sense of personal achievement or a conscious fulfillment known as intrinsic rewards. More than any tangible things that motivate people to form volunteering, intrinsic motivational factors pose a much deeper motive from the person engaged in volunteer work because of the fact that this type of motivation arises from within the person himself (Alumni, 2014). Hao et al. (2018) argued that intrinsic motivation for volunteering is positively related to affective commitment and job satisfaction. Furthermore, Stukas et al. (2016) and Alam and Campbell (2017) acknowledged the importance of intrinsic motivations in the sustainment of volunteer involvement.

People are social beings that need belongingness and love. People seek interpersonal relationships to motivate their behavior (McLeod, 2020). Most people appreciate being in a group or team atmosphere and are motivated to participate and have the willingness to cooperate in such an atmosphere as in the idea of "Esprit de Corps" or team spirit - it is the excitement and fun of being part of something greater than oneself (Ford et al., 2012; King \& Cichy, 2006). A volunteer program in a major sporting event has the ability to satisfy this social aspect of human needs, for it involves numerous circumstances of socialization in the conduct of volunteering works. Dekkak (2020) and Zalloum (2011) concluded that volunteering help develops the social network between people involved in the worthy cause and improve social connections and associations among different sectors of the community. Socialization starts several months before the actual event; it involves activities and trainings with the other volunteers and sport event organizers such as launching and welcome party, solidarity party and team building activities which promote socialization among those involved. Socialization is even greater in the actual event where volunteers meet diverse people aside from their co-volunteers, including the athletes, sports 
officials, media personnel, government officials and thousands of local and foreign spectators attending the games.

Schaufeli and Bakker (2004) defined engagement as fulfilling, positive, and work-related state of mind which is characterized by commitment, interest and vigor. Terry (2020) cited Kahn in his paper published in 1990, who categorized employee (volunteer) engagement into three dimensions - cognitive, emotional and physical. Cognitive engagement is focusing a great deal of attention on activities, while emotional engagement is being enthusiastic about volunteering activities and giving a sense of pride and inspiration on performing one's volunteer works. On the other hand, physical engagement means exercising a lot of energy when volunteering, feeling strong and vigorous.

In the corporate world, management can promote the spirit of volunteerism to their employees by giving them the chance to partake in volunteering activities, as posited in several studies. Booth et al. (2009) suggested that employees are engaged to volunteer works if employers offer support and applying the gift exchange theory, while Caligiuri et al. (2012) found out that the most valuable volunteer acts are when participations are intentional. Furthermore, Alfes et al. (2016) revealed the positive relationship of emotion-oriented and task-oriented support from the organization to volunteer engagement. Although sport event volunteers do not receive monetary benefit, unlike paid employees, engagement theory is also applicable on volunteer management which Allen and Bartle (2014) concluded in their study that volunteers' engagement has a relationship to their primary motivations and proper management is also vital. With this premise, this study suggests that the motives and concerns of the volunteers are factors that influence volunteer engagement significantly with their personal effort, time and skills. Hence, this study hypothesizes:

Hypothesis 1: Community contribution significantly influences volunteer engagement.

Hypothesis 2: Skill enrichment significantly influences volunteer engagement.

Hypothesis 3: Connection with sport significantly influences volunteer engagement. Hypothesis 4: Privileges of volunteering significantly influences volunteer engagement. Hypothesis 5: Positive life experiences significantly influences volunteer engagement. Hypothesis 6: Social enrichment significantly influences volunteer engagement.

Several studies proved that high levels of engagement of the volunteers produce valuable outcomes like extended time volunteering (Shantz et al., 2014; Gagne, 2003), personal satisfaction, enthusiasm and intent to continue with the volunteering works (Vecina et al., 2012). The study conducted by Grant (2012) proved that volunteers have motives in participating in volunteer works that trigger their engagement, and when these motives are satisfied, employees repeat their participation. Volunteer engagement has a positive relationship to intent to stay in the voluntary organization, as revealed in the study of Alfes et al. (2016). Moreover, the satisfaction of volunteer motivations was found out to have a significant relationship to future intention to volunteer (Kim et al. 2020; Wang \& Yu 2015). Therefore, an additional hypothesis is proposed in this study that volunteer engagement is related with intent to volunteer in the future. 
Hypothesis 7: Volunteer engagement significantly influences intention to volunteer in the future

Moreover, proper volunteer management was associated with high levels of volunteer maintenance, and intention to volunteer to other events in the future (Cuskelly et al., 2006), and volunteer's positive experience might influence their decision in involving themselves in volunteer works in the future. The study conducted by Kim et al. (2020) revealed that the overall satisfaction of volunteer motivations has a significant relationship with the volunteers' future intention for volunteerism which is supportive of the previous research study of Wang and Yu (2015). Hence, proposing the following hypotheses:

Hypothesis 8: Community contribution significantly influences intention to volunteer in the future. Hypothesis 9: Skill enrichment significantly influences intention to volunteer in the future.

Hypothesis 10: Connection with sport significantly influences intention to volunteer in the future. Hypothesis 11: Privileges of volunteering significantly influences intention to volunteer in the future.

Hypothesis 12: Positive life experiences significantly influences intention to volunteer in the future. Hypothesis 13: Social enrichment significantly influences intention to volunteer in the future.

Volunteer engagement serves as a mediating factor of the relationship between sport event volunteers' motivations in doing volunteer works and their intention to volunteer in the future. From a significant level of fulfillment of volunteers, motivation will lead to a significant level of intention to volunteer in the future because of the significant level of engagement in their roles as volunteers. Accordingly, this study hypothesizes that volunteer engagement mediates the relationship between volunteer motivations and the intention to volunteer in the future:

Hypothesis 14: Volunteer engagement significantly mediates the relationship between community contribution and intention to volunteer in the future.

Hypothesis 15: Volunteer engagement mediates the relationship between skill enrichment and intention to volunteer in the future.

Hypothesis 16: Volunteer engagement mediates the relationship between connection with sport and intention to volunteer in the future.

Hypothesis 17: Volunteer engagement mediates the relationship between privileges of volunteering and intention to volunteer in the future.

Hypothesis 18: Volunteer engagement mediates the relationship between positive life experience and intention to volunteer in the future.

Hypothesis 19: Volunteer engagement mediates the relationship between social enrichment and intention to volunteer in the future.

This study intends to establish a structural model that describes the effect of motivation and engagement on the future volunteering intention in an international sporting event aiming to provide implications for event organizers and volunteer coordinators to effectively retain experienced volunteers and motivate them to engage for future events. Specifically, it seeks to answer the following questions: (1) What is the motivation of volunteers in volunteering in an 
international sporting event in terms of the following: community contribution, skill enrichment, connection with the sport, privileges of volunteering, positive life, experience, and social enrichment?; (2) What is the volunteer engagement and future volunteering intentions of volunteers in an international sporting event?; (3) To what extent do volunteer motivations significantly influence volunteer engagement? (4) To what extent does volunteer engagement significantly influence future volunteering intention? (5) To what extent does volunteer engagement mediate the relationship between volunteer motivations and future volunteering intention?

\section{Research Framework}

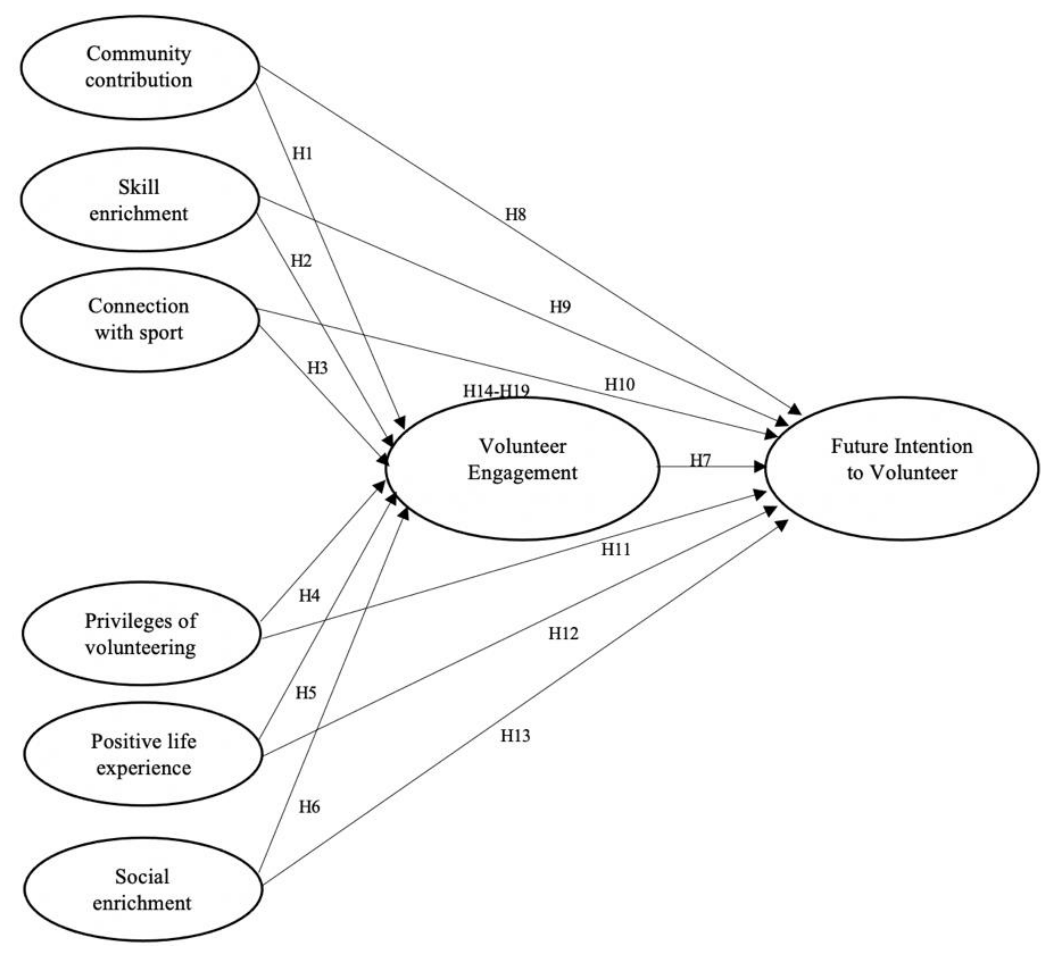

Figure 1. Research Framework

This study is anchored from theoretical frameworks based on the social exchange theory, engagement theory, and gift exchange theory, where volunteers do volunteer works with their altruistic, intrinsic and extrinsic motives with an expectation of gaining something, and people are engaged to volunteer works if they are offered support and provided with rewards (Miles 2012, Khan 1990 as cited by Young 2018, Booth et al., 2009). To depict the overall premise of the study, the researcher formulated a research framework which is illustrated in figure 1. The figure shows the important motives and concerns related to volunteering. The exogenous variables are directed to the endogenous variables, which might pose significant relationships to the level of engagement of the respondents as mediating factor to their intent to volunteer in the future. 
Moreover, the study theorizes the mediating effect of engagement between volunteer motivations and future volunteering intention basing on the study of Grant (2012), showing the satisfaction of the volunteer motives trigger their engagement which results from repeating participation.

\section{RESEARCH METHOD}

Predictive-causal research design was applied in the conduct of the study; this is to analyze the motivations of sport events' volunteers as they relate to volunteer engagement as mediating factor toward their intention to volunteer in the future using online and administered survey.

The participants of the study were the sport event volunteers in the 30th SEA Games - Clark Cluster. The respondents were selected using non-probability sampling, specifically purposive sampling. The researcher selected the partner educational institutions which participated in the volunteer program as the respondents of the study, mainly from the province of Pampanga where most of these institutions are located; additionally, some random respondents were also considered coming from the social media groups of the volunteers. Respondents were selected with the following qualifying criteria - first, they volunteered at the 30th SEA Games deployed at Clark cluster venues; second, they completed at least four volunteer working days, which was the minimum days set by PHISGOC; and lastly, they did not receive monetary compensation in the performance of his or her duty. The target minimum sample size is between 146-160 (146 for gamma exponential-method and 160 for inverse square root method), which was determined using WarpPLS software under statistical power and minimum sample size requirement function that allows researchers to draw estimation of the minimum sample size (Kock and Hadaya, 2018) with 0.197 minimum absolute significant path coefficient, .05 significance level, and .80 power level. The response rate was $100 \%$ having 168 actual total respondents exceeding the target minimum sample size, sufficient to justify the outcome of the structural model test.

The demographic profile of the respondents is shown in Table 1. Based on the variable sex, the respondents are closed in numbers with the percentages of $55 \%$ and $45 \%$ for female and male respectively, while $90 \%$ of the respondents are within the age range of 18-30 years, mostly singles at $93 \%$. These numbers are consistent with the educational background of the majority of the respondents coming from high school (16\%) and college (72\%) levels since PHISGOC mainly targeted the educational institutions as their partners for the volunteer program. The actual total number of respondents was 168, exceeding the target minimum sample size of 160 .

Table 1. Respondents' Demographic Profile

\begin{tabular}{llll}
\hline Variable & Description & Frequency & Percentage \\
\hline Sex & Male & 75 & $44.64 \%$ \\
& Female & 93 & $55.36 \%$ \\
Age & $18-20$ & 98 & $58.33 \%$ \\
& $21-30$ & 54 & $32.14 \%$ \\
\multirow{3}{*}{ Marital Status } & $31-40$ & 12 & $7.14 \%$ \\
& 41 -above & 4 & $2.38 \%$ \\
& Single & 156 & $92.86 \%$ \\
& Married & 11 & $6.55 \%$ \\
& Widowed & 1 & $0.60 \%$
\end{tabular}


Journal of Social Entrepreneurship Theory and Practice (JSETP), Vol. 1 (1), 28-50

The Role of Engagement on the Relationship Between Motivation and Future Volunteering Intention: The

Case of the 30th Southeast Asian Games

Roel S. Agustin

\begin{tabular}{llll} 
Educational Level & Graduate Studies & 5 & $2.98 \%$ \\
& Bachelor's Degree & 15 & $8.93 \%$ \\
& College Level & 121 & $72.02 \%$ \\
& High School & 27 & $16.07 \%$ \\
\hline
\end{tabular}

A structured survey questionnaire was adapted by the researcher and utilized to analyze the levels of motivations (Doherty, 2009), engagement (Harp et al., 2017) and future volunteering intention (Doherty, 2009) of sport event volunteers using a 7-point Likert Scale. The first part includes the elements in determining the motives and concerns related to volunteering as main variables and bases of the study through community contribution (8 items), skill enrichment (4 items), connection with sport (4 items), privileges of volunteering (5 items), positive life experience (3 items), and social enrichment (3 items), measured with a 7-point Likert Scale (1 completely disagree to 7 completely agree). The second part of the instrument analyzed the volunteer engagement with 6 items and gauged with a 7-point Likert Scale 11 completely disagree to 7 completely agree). The last part, future intention to volunteer with 3 items was also measured with a 7-point Likert Scale by the likelihood to volunteer for another event (1 definitely would not volunteer to 7 definitely would volunteer), the extent of involvement in a future event (1 to an extremely small extent to 7 to an extremely large extent), and the level of volunteering in the community ( 1 will greatly decrease to 7 will greatly increase). The researcher slightly modified the original instruments to fit the setting of the study, such as specifying SEA Games as the sporting event involved and rephrasing the questions into a declarative format, transforming them into complete sentences. Presented in Table 3 is the research instrument's test on its validity and reliability.

The researcher distributed the survey questionnaires to the respondents personally and online through Google Forms which started March 2020 and ended in December 2020. Respondents who answered the survey, which was administered personally, were retrieved on the same day, while online surveys were sent back at least one day after. The data were processed into statistical data using WarpPLS-SEM and translated into meaningful information. Inferential statistic was used in analyzing the data collected through the online and administered survey. WarpPLS was utilized to find the significant influence of the exogenous and endogenous variables using Structural Equation Modelling (SEM). PLS-SEM was applied to this study to analyze the complexity of the structural model that described the effects of volunteer motivation on engagement and future volunteering intention. Likewise, PLS-SEM analyzed the mediating effects of engagement between the variables motivation and intention to volunteer in the future.

Cronbach alpha, model fit and quality indices, square root of average variance extracted (AVE) coefficients, and heterotrait-monotrait (HTMT) ratios were also computed to test the validity and reliability of the instrument.

\section{FINDINGS AND DISCUSSION}

Two stages were involved in data analysis. The first stage tested the validity and reliability of the constructs, and the second stage assessed the structural model and analyzed the relationships of the hypotheses. Below are the results generated in utilizing PLS-SEM. 


\section{Measurement Model Assessment Results}

Table 2 shows the model fit and quality indices of SEM. According to Kock (2020), the pvalues of APC, ARS, and AARS must be less than or equal to .05. Thus, the results generated in this study are acceptable. As for AVIF and AFVIF, the indices must be less than or equal to 5 (ideally less than or equal to 3.3); based on the results, AVIF and AFVIF are within the acceptable value range. The GoF result of this study was found to be large since it is greater than .36 (small if greater than or equal to .1 and medium if greater than or equal to .25 ).

Table 2. Model Fit and Quality Indices

\begin{tabular}{|c|c|c|}
\hline Indices & Coefficients & \\
\hline Average path coefficient (APC) & $0.129, p=.022$ & $\mathrm{p}</=.05$ \\
\hline Average R-squared (ARS) & $0.531, p<0.001$ & $\mathrm{p}</=.05$ \\
\hline Average adjusted R-squared (AARS) & $0.498, p<0.001$ & $\mathrm{p}</=.05$ \\
\hline Average block VIF (AVIF) & 3.275 & $\begin{array}{l}\text { Acceptable if }</=5 \text {; } \\
\text { Ideal if }</=3.3\end{array}$ \\
\hline Average full collinearity VIF (AFVIF) & 4.258 & $\begin{array}{l}\text { Acceptable if }</=5 \text {; } \\
\text { Ideal if }</=3.3\end{array}$ \\
\hline Tenenhaus GoF (GoF) & 0.659 & $\begin{array}{l}\text { Small }>/=.1 ; \text { Medium } \\
>/=.25 \\
\text { Large }>/=.36\end{array}$ \\
\hline
\end{tabular}

The assessment of the measurement model is presented on Table 3 . The validity and reliability of the variable constructs were assessed using PLS-SEM. The results showed that all factors of validity satisfied the standard values for factor loading of $>.5$ (should be higher than .5) and average variance extracted (AVE) of $>.5$ (should be greater than .5) and p-values must be equal to or lower than .05 (Hair et al., 2014). As for the composite reliability (CR) and Cronbach's alpha, Taber (2017) stated that values with .7 or higher signify internal consistency. Thus, all variables included were found to be reliable.

Presented in Table 4 are the results of the discriminant validity test of the research instrument. Discriminant validity measures the items in each variable whether they pose confusion on the part of the respondents when answering the survey questionnaire (Kock, 2020; Lacap, 2019); this is to ensure that reflective constructs have the strongest association with its own variable (Hair et al., 2017). The results suggest that the study has discriminant validity since the square root of the AVE coefficients are more than the other correlation coefficients involving the variable itself (Fornell \& Larcker, 1981 as cited by Lacap, 2019).

Table 3. Measurement Model Assessment

\begin{tabular}{|c|c|c|c|c|}
\hline Variable & $\begin{array}{c}\text { Loading } \\
(>.5)\end{array}$ & $\begin{array}{c}\text { Cronbach's } \\
\text { Alpha } \\
(a>.7)\end{array}$ & $\begin{array}{c}\text { Composite } \\
\text { Reliability } \\
(C R>.7)\end{array}$ & $\begin{array}{l}\text { Average } \\
\text { Variance } \\
\text { Extracted } \\
(A V E>.5)\end{array}$ \\
\hline Community contribution & & 0.897 & 0.919 & 0.592 \\
\hline MCC1 & 0.816 & & & \\
\hline MCC2 & 0.823 & & & \\
\hline MCC3 & 0.839 & & & \\
\hline 38 & & & & \\
\hline
\end{tabular}


Journal of Social Entrepreneurship Theory and Practice (JSETP), Vol. 1 (1), 28-50

The Role of Engagement on the Relationship Between Motivation and Future Volunteering Intention: The Case of the 30th Southeast Asian Games

Roel S. Agustin

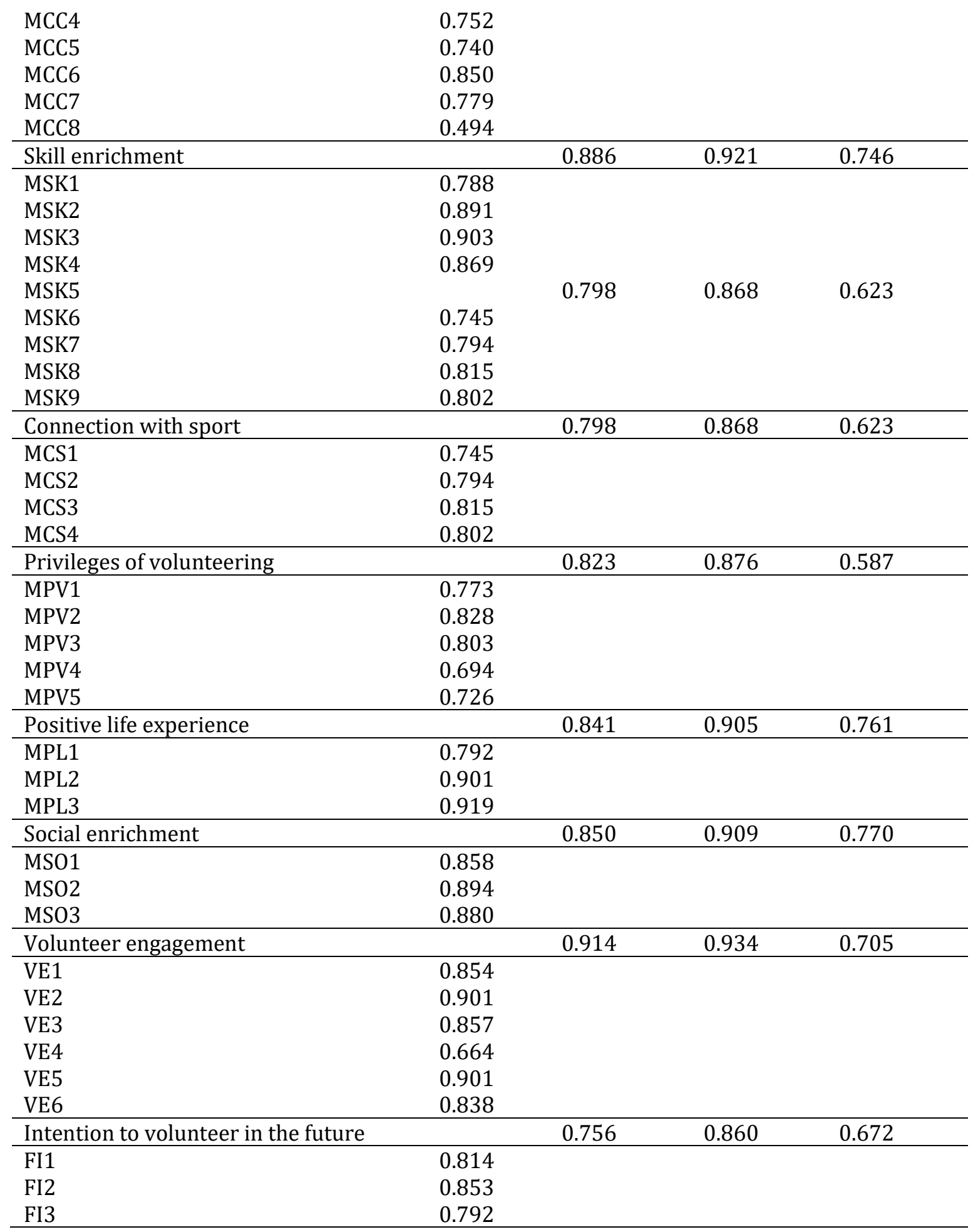


Journal of Social Entrepreneurship Theory and Practice (JSETP), Vol. 1 (1), 28-50

The Role of Engagement on the Relationship Between Motivation and Future Volunteering Intention: The Case of the 30th Southeast Asian Games

Roel S. Agustin

\begin{tabular}{lllllllll}
\hline & \multicolumn{8}{c}{ Table 4. Square Root of AVE Coefficients and Correlation Coefficients } \\
\hline & MCC & MSK & MCS & MPV & MPL & MSO & VE & FI \\
\hline MCC & $\mathbf{. 7 6 9}$ & & & & & & & \\
MSK & .524 &. $\mathbf{8 6 4}$ & & & & & & \\
MCS & .250 & .300 &. $\mathbf{7 8 9}$ & & & & & \\
MPV & .342 & .318 & .465 & .766 & & & & \\
MPL & .480 & .598 & .392 & .439 & .873 & & & \\
MSO & .466 & .441 & .185 & .286 & .465 &. $\mathbf{8 7 7}$ & & \\
VE & .439 & .769 & .346 & .404 & .616 & 507 & $\mathbf{. 8 4 0}$ & \\
FI & .492 & .540 & .235 & .239 & .434 & .380 & .563 & $\mathbf{. 8 2 0}$ \\
\hline
\end{tabular}

Note: Square roots of AVE are shown on diagonal.

In addition, Table 5 shows the calculated heterotrait-monotrait (HTMT) ratios. According to Kock (2020), HTMT ratios have been recommended for discriminant validity assessment for composite-based SEM. Further, Henseler et al. (2014) concluded that HTMT is superior to other traditional criteria used in measuring discriminant validity because HTMT attains great sensitivity and specificity rates throughout all simulation conditions. The measurement instrument is said to have a good discriminant validity of the questions related to each latent variable do not confuse the respondents in understanding the instrument in terms of their meaning and construct. Based on standard measures, the measurement instrument is good if the ratio is less than $.90(<.90$; liberal $)$ and best if less than .85 ( $<.85$; conservative). This study found that discriminant validity has been established on the measurement instrument based on more conservative .85 threshold value.

Table 5. HTMT Ratios

\begin{tabular}{lllllllll}
\hline & MCC & MSK & MCS & MPV & MPL & MSO & VE & FI \\
\hline MCC & & & & & & & & \\
MSK & .592 & & & & & & & \\
MCS & .318 & .356 & & & & & & \\
MPV & .417 & .381 & .572 & & & & & \\
MPL & .559 & .680 & .473 & .528 & & & & \\
MSO & .526 & .506 & .228 & .350 & .555 & & & \\
VE & .486 & .849 & .404 & .471 & .690 & .579 & & \\
FI & .600 & .664 & .307 & .322 & .548 & .476 & .682 & \\
\hline
\end{tabular}

Good if $<.90$, best if $<.85$

\section{Path Analysis between Volunteer Motivations and Volunteer Engagement}

The structural model and hypotheses testing were analyzed by calculating the path coefficients (ㅁ), p-values, standard errors (SE), and effect sizes (f2) using PLS-SEM (Kock, 2020). Presented in Table 6 are the structural model estimates that tested the hypothesis relationships of the variable constructs. Figure 4 shows the results of the tested structural model, based on the calculated values, skills enrichment $($ ? $=.616$; $\mathrm{p}<.001)$, privileges of volunteering ( $0=.136 ; \mathrm{p}<$ $.036)$, and social enrichment ( $0=.143 ; \mathrm{p}<.029)$ positively influence volunteer engagement. Positive path coefficients indicate that as skill enrichment, privileges of volunteering, and social enrichment increase, volunteer engagement also increases, this means that for every one-unit increase in skills enrichment leads to .616 increase in volunteer engagement, also, for every one- 
unit increase in privileges of volunteering leads to .136 increase in volunteer engagement, further, for every one-unit increase in social enrichment leads to .143 increase in volunteer engagement. The R2 $=.692$ suggests that $69.2 \%$ of the variability of volunteer engagement can be rationalized by skills enrichment, privileges of volunteering, and social enrichment and the other $31.8 \%$ can be rationalized by the other variables. On the other hand, community contribution ( $0=-.028 ; p=.358$ ), connection with sports ( $($ l $=.036 ; \mathrm{p}=.320)$, and positive life experiences ( $=.089 ; \mathrm{p}=.122)$ do no significantly influence volunteer engagement.

\section{Path Analysis between Volunteer Motivations and Intention to Volunteer in the Future}

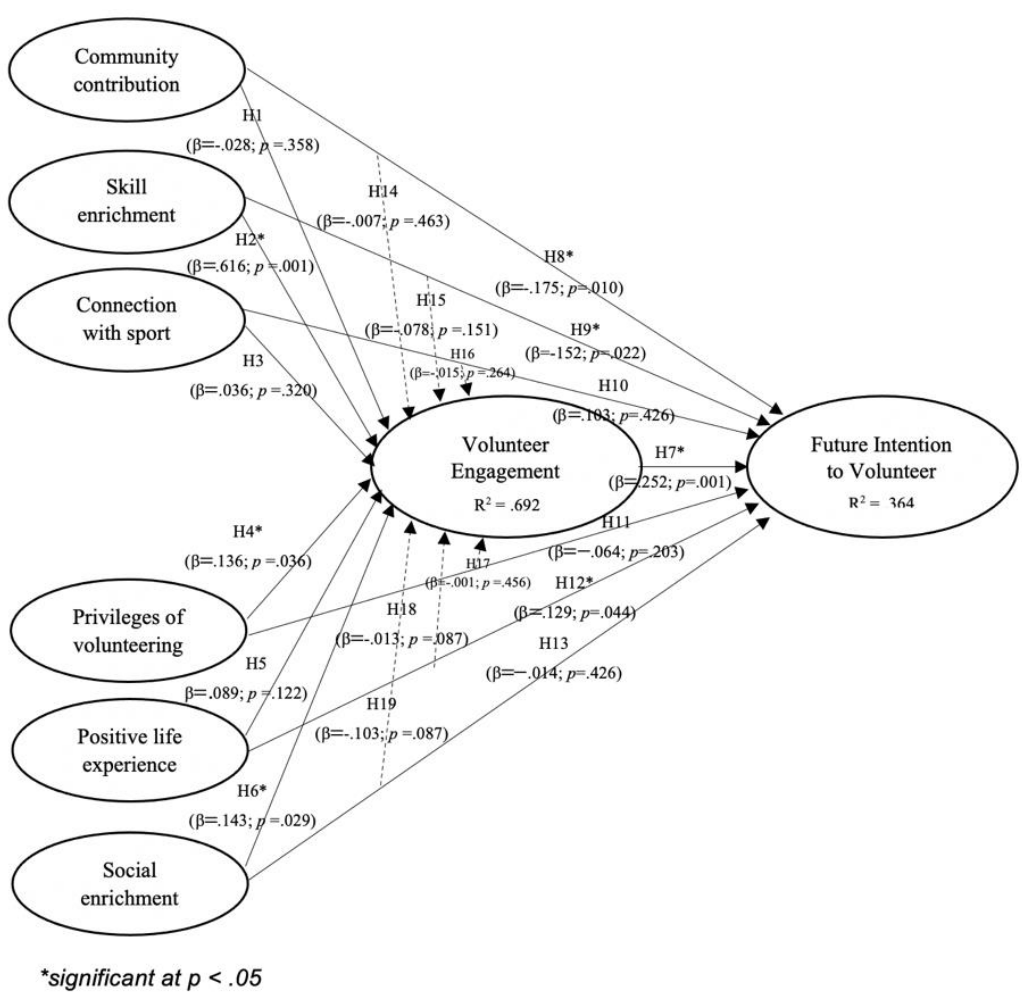

Figure 2. Tested Model Results

Figure 2 also presents the results on the path analysis between volunteer motivation variables and future intention to volunteer. Based on the results, community contribution ( 0.175 ; $\mathrm{p}<.010$ ), skills enrichment ( $=.152 ; \mathrm{p}<.022$ ), positive life experiences ( $\mathrm{l}=.129 ; \mathrm{p}<.044$ ), and volunteer engagement ( $0.252 ; \mathrm{p}<.001$ ) positively influence intention to volunteer in the future. Similarly, positive path coefficients indicate that as community contribution, skill enrichment, positive life experiences, and volunteer engagement increase, future intention to volunteer also increases, this means that for every one unit increase in community contribution, skills enrichment, positive life experiences, and volunteer engagement led to $.175, .152, .022$, and .252 increase in 
intention to volunteer in the future respectively. The $\mathrm{R} 2=.364$ suggests that $36.4 \%$ of the variability of intention to volunteer in the future can be justified by community contribution, skills enrichment, positive life experiences, and volunteer engagement and the remaining $63.6 \%$ can be justified by the other variables. Moreover, connection with sport ( $=.103 ; \mathrm{p}=.087$ ), privileges in volunteering ( ? = -.064; $\mathrm{p}=.203)$, social enrichment ( $\mathrm{l}=-.014 ; \mathrm{p}=.426)$ do no significantly influence intention to volunteer in the future.

\section{Test of Mediation Results}

PLS-SEM was utilized to analyze mediation effects (Carrion et al., 2018). Testing the model with volunteer engagement as the mediating factor between six volunteer motivation variables and intention to volunteer in the future resulted to $0=-.007$ non-significant at $\mathrm{p}=.463$ (SE $=.077$; $\mathrm{f} 2=$ .002 ) for community contribution; $0=-.078$ non-significant at $\mathrm{p}=.151$ (SE $=.076$; $\mathrm{f} 2=.025$ ) for skill enrichment; $0=-.048$ non-significant at $p=.263$ (SE $=.076$; $\mathrm{f} 2=.013$ ) for connection with sport; 0 ? $=-.015$ non-significant at $\mathrm{p}=.264(\mathrm{SE}=.075 ; \mathrm{f} 2=.020)$ for privileges of volunteering; 0 -.001 non-significant at $\mathrm{p}=.496(\mathrm{SE}=.077 ; \mathrm{f} 2=.000$ ) for positive life experiences; 0 - $=-103$ nonsignificant at $\mathrm{p}=.087(\mathrm{SE}=.075$; $\mathrm{f} 2=.038$ ) for social enrichment. Given the above analyses, the mediating role of volunteer engagement between community contribution, skill enrichment, connection with sport, privileges of volunteering, positive life experiences, social enrichment and intention to volunteer in the future does not suggest significant relationships among the variables. Therefore, H14 to H19 are not supported.

Table 6. Structural Model Estimates

\begin{tabular}{|c|c|c|c|c|}
\hline Path (Hypotheses) & $\begin{array}{c}\text { Path Coefficient } \\
\beta \\
\end{array}$ & p-Value & SE & $\mathbf{f}^{2}$ \\
\hline (H1) MCC $\rightarrow$ VE & -0.028 & $\begin{array}{c}0.358 \\
\text { (not } \\
\text { supported) }\end{array}$ & 0.077 & 0.013 \\
\hline$(\mathrm{H} 2) \mathrm{MSK} \rightarrow \mathrm{VE}$ & 0.616 & $\begin{array}{c}<0.001^{*} \\
\text { (supported) }\end{array}$ & 0.068 & 0.497 \\
\hline$(\mathrm{H} 3) \mathrm{MCS} \rightarrow \mathrm{VE}$ & 0.036 & $\begin{array}{c}0.320 \\
\text { (not } \\
\text { supported) }\end{array}$ & 0.077 & 0.014 \\
\hline (H4) MPV $\rightarrow$ VE & 0.136 & $\begin{array}{c}0.036^{*} \\
\text { (supported) }\end{array}$ & 0.075 & 0.063 \\
\hline (H5) MPL $\rightarrow$ VE & 0.089 & $\begin{array}{c}0.122 \\
\text { (not } \\
\text { supported) }\end{array}$ & 0.076 & 0.059 \\
\hline (H6) MSO $\rightarrow$ VE & 0.143 & $\begin{array}{c}0.029^{*} \\
\text { (supported) }\end{array}$ & 0.075 & 0.073 \\
\hline (H7) VE $\rightarrow$ FI & 0.252 & $\begin{array}{c}<0.001^{*} \\
\text { (supported) }\end{array}$ & 0.073 & 0.148 \\
\hline$(\mathrm{H} 8) \mathrm{MCC} \rightarrow \mathrm{FI}$ & 0.175 & $\begin{array}{c}0.010^{*} \\
\text { (supported) }\end{array}$ & 0.074 & 0.088 \\
\hline (H9) MSK $\rightarrow$ FI & 0.152 & $\begin{array}{c}0.022^{*} \\
\text { (supported) }\end{array}$ & 0.075 & 0.083 \\
\hline
\end{tabular}


Journal of Social Entrepreneurship Theory and Practice (JSETP), Vol. 1 (1), 28-50

The Role of Engagement on the Relationship Between Motivation and Future Volunteering Intention: The Case of the 30th Southeast Asian Games

Roel S. Agustin

\begin{tabular}{|c|c|c|c|c|}
\hline$(\mathrm{H} 10) \mathrm{MCS} \rightarrow \mathrm{FI}$ & 0.103 & $\begin{array}{c}0.087 \\
\text { (not } \\
\text { supported) }\end{array}$ & 0.076 & 0.038 \\
\hline (H11) MPV $\rightarrow$ FI & -0.064 & $\begin{array}{c}0.203 \\
\text { (not } \\
\text { supported) }\end{array}$ & 0.076 & 0.024 \\
\hline (H12) MPL $\rightarrow$ FI & 0.129 & $\begin{array}{c}0.044^{*} \\
\text { (supported) }\end{array}$ & 0.075 & 0.065 \\
\hline (H13) MSO $\rightarrow$ FI & -0.014 & $\begin{array}{c}0.426 \\
\text { (not } \\
\text { supported) }\end{array}$ & 0.077 & 0.006 \\
\hline$(\mathrm{H} 14) \mathrm{MCC} \rightarrow \mathrm{VE} \rightarrow \mathrm{FI}$ & -0.007 & $\begin{array}{c}0.463 \\
\text { (not } \\
\text { supported) }\end{array}$ & 0.077 & 0.002 \\
\hline$(\mathrm{H} 15) \mathrm{MSK} \rightarrow \mathrm{VE} \rightarrow \mathrm{FI}$ & 0.078 & $\begin{array}{c}0.151 \\
\text { (not } \\
\text { supported) }\end{array}$ & 0.076 & 0.025 \\
\hline$(\mathrm{H} 16) \mathrm{MCS} \rightarrow \mathrm{VE} \rightarrow \mathrm{FI}$ & -0.048 & $\begin{array}{c}0.263 \\
\text { (not } \\
\text { supported) }\end{array}$ & 0.076 & 0.013 \\
\hline$(\mathrm{H} 17) \mathrm{MPV} \rightarrow \mathrm{VE} \rightarrow \mathrm{FI}$ & -0.015 & $\begin{array}{c}0.264 \\
\text { (not } \\
\text { supported) }\end{array}$ & 0.075 & 0.020 \\
\hline (H18) MPL $\rightarrow$ VE $\rightarrow$ FI & -0.001 & $\begin{array}{c}0.496 \\
\text { (not } \\
\text { supported) }\end{array}$ & 0.077 & 0.000 \\
\hline (H19) MSO $\rightarrow$ VE $\rightarrow$ FI & 0.103 & $\begin{array}{c}0.087 \\
\text { (not } \\
\text { supported) }\end{array}$ & 0.075 & 0.038 \\
\hline
\end{tabular}

*Significant at $\mathrm{p}<.05$

\section{Discussion}

Based on the results and findings of the study, all factors highly influenced the volunteers in their decision to participate in the 30th SEA Games volunteer program. The overall ratings of the 5 variables - community contribution, skill enrichment, connection with sport, privileges of volunteering, and positive life experience were "mostly agree" (5.50-6.49) while the social enrichment variable was rated the highest - "completely agree" (6.50-7.00) by the respondents. These results comply with the social exchange theory, which states that people involve themselves and uphold exchange relationships with the hope that doing so is rewarding and from various studies of Kim et al. (2020), Vetitnev et al. (2019), Wang and Yu (2015) and Doherty (2009).

The respondents were highly engaged with their volunteer works as reflected on their overall ratings of 6.46 , corresponding to "mostly agree." Volunteers completely agreed that they were proud of the volunteer works they did (6.74) and that they were inspired by their individual assignments (6.54). Similar to the findings of Caligiuri et al. (2012), they concluded that the most | 43 
valuable volunteer acts are when participations are intentional and intrinsic in nature. Hence, the intention to volunteer in the future was also positively considered by the respondents, with 6.43 overall rating indicating that they "would very probably volunteer in the future."

This study found that skill enrichment, privileges of volunteering, and social enrichment positively influence volunteer engagement, comparable to the studies made by Mecbure and Selen (2020), Kim et al. (2020), Graves (2019), Stukas et al. (2016) and Allen and Bartle (2014), which revealed that volunteers' engagement has a relationship to their primary motivations. The significant assessment on the relationships among the variables analyzed shows that $\mathrm{H} 2, \mathrm{H} 4$, and H6 are supported, while community contribution, connection with sports, and positive life experiences did not significantly influence volunteer engagement; therefore, $\mathrm{H} 1, \mathrm{H} 3$, and $\mathrm{H} 5$ are not supported, although there are findings that these intrinsic motivations were predictors of volunteer engagement, such as the studies of Kim et al. (2019) and Allen and Bartle (2014), they concluded that advancing intrinsic motivations may help event organizers develop a high level of volunteer engagement.

On the respondents' future volunteering intention, the study found that community contribution, skill enrichment, positive life experiences, and volunteer engagement positively influenced intention to volunteer in the future, consistent with the findings of the studies of Alfes et al. (2016), Shantz et al. (2014), and Gagne (2003), hence, H7, H8, H9, and H12 are supported, whereas, connection with sport, privileges in volunteering, and social enrichment did not significantly influence intention to volunteer in the future, thus, H10, H11, and H13 are not supported, in contrast, Kim et al. (2019), Doherty (2009), Downward and Ralston (2006) found that personal and social development significantly influenced sport volunteers' involvement in future volunteering endeavors.

Based on the SEM analysis conducted, the study found that the mediating role of volunteer engagement between community contribution, skill enrichment, connection with the sport, privileges of volunteering, positive life experiences, social enrichment and intention to volunteer in the future did not show a significant relationship among the variables. Therefore, H14 to H19 are not supported. This means that volunteers' decision for future volunteering intention is directly influenced by their motives (specifically community contribution, skill enrichment and positive life experiences) and do not need the mediating effect of the engagement.

\section{CONCLUSION}

The main goal of this study was to establish a structural model that describes the effect of motivation and engagement on the future volunteering intention in an international sporting event. Moreover, it aimed to provide implications for event organizers and volunteer coordinators to effectively retain experienced volunteers and motivate them to engage in future events. The results and findings of the study conclude that (1) community contribution, skill enrichment, connection with sport, privileges of volunteering, positive life experiences, and social enrichment greatly motivated the volunteers to participate in the 30th SEA Games volunteer program; (2) the volunteers were significantly engaged with their assignments during the 30th SEA Games, moreover, their intention to volunteer in the future was similarly favorable; (3) skill enrichment, privileges of volunteering, and social enrichment positively influenced volunteer engagement, therefore, $\mathrm{H} 2, \mathrm{H} 4$, and $\mathrm{H} 6$ are supported, on the other hand, community contribution, connection 
with sports, and positive life experiences did not significantly influence volunteer engagement, hence, H1, H3, and H5 are not supported; (4) community contribution, skill enrichment, positive life experiences, and volunteer engagement positively influenced intention to volunteer in the future, thus, H7, H8, H9, and $\mathrm{H} 12$ are supported, while connection with sport, privileges in volunteering, and social enrichment did not significantly influence intention to volunteer in the future, therefore, H10, H11, and H13 are not supported; and (5) volunteer engagement did not mediate community contribution, skill enrichment, connection with sport, privileges of volunteering, positive life experiences, social enrichment to intention to volunteer in the future, hence, H14 to H19 are not supported.

\section{Study Implications, Limitations, and Future Research Directions}

Based on the findings of the study, the researcher has the following recommendations: first, almost all sport event volunteers are motivated by their personal and social needs, sport event organizers must ensure to provide these extrinsic rewards to attract and maintain them to actively participate in volunteer work. The majority of the respondents appreciate interacting and working with the other volunteers and having more opportunities to make friends. Sport event organizers must create more ways for social interactions and enrichment by conducting team-building and social gathering (launching, training, volunteers' solidarity night, etc.) as pre-Games activities, rotating venue and schedule assignments during the Games, and forming a private group on social media for virtual socialization even after the Games. Second, volunteers are more engaged when they feel proud and inspired by their volunteer works. Although engagement by people to any task they do may come primarily as an intrinsic factor, sport event organizers must provide emotional support to the volunteers to boost their morale to feel proud and inspired in fulfilling their tasks as sports volunteers. Furthermore, sport event organizers must also ensure that the skills of the volunteers will be enhanced, privileges as volunteers will be rewarded, and opportunities for social enrichment will be realized since the study found that these motivations positively influenced volunteer engagement and according to Allen and Bartle (2014) volunteers' engagement has a significant relationship to their primary motivations. Finally, the satisfaction of volunteer motivations and volunteer engagement predict future intention to volunteer. Hence, sport event organizers must consistently satisfy the volunteers' motivational needs, particularly community contribution, skill enrichment, positive life experiences, and volunteer engagement which are intangible in nature. Sport event organizers must ensure that volunteers receive moral support and feel that they contributed something valuable to their community and gain positive life experiences by proper volunteer work design, efficient training and development, and an inclusive working environment.

In the course of this study, some limitations were identified. First, this study is limited to the assessment of volunteer motivations as they relate to volunteer engagement and intention to volunteer in future events. Future research may consider adding another set of variables relating to the cost of sports event volunteering, such as personal inconvenience and volunteer assignment overload other than the benefits of sports event volunteering. Second, the targeted participants of the study were the volunteers of the 30th SEA Games - Clark Cluster, mostly from the partner educational institutions in Pampanga purposively selected by the researcher; hence, the outcomes 
of the study are just limited to this volunteer group. Future research may widen the scope of the study by extending the participants coming from the other clusters and partner organizations. Third, respondents assigned in sport services may have answered favorably in the motivation variables since they experienced being in the actual Games and had more opportunities to interact with the athletes and other volunteers. It may be recommended to find the differences in the level of volunteer motivations, volunteer engagement, and future volunteering intention based on the respondent's demographic characteristics such as sex, age, employment, marital status, and their area of assignment, which is also beneficial in managing sports volunteer especially that different segments have different needs and expectations. Lastly, future research may also analyze the gap between volunteer pre-event expectations and actual volunteering experiences to better understand volunteer satisfaction that may influence their engagement and intention to participate in future volunteering programs.

\section{REFERENCES}

Allen, J. \& Bartle, M. (2014) Sport event volunteers' engagement: management Matters. Managing Leisure, 19:1, 36 50. http://doi.org/10.1080/13606719.2013.849502

Alfes, K., Shantz, A., \& Bailey, C. (2016). Enhancing Volunteer Engagement to Achieve

Desirable Outcomes: What Can Non-profit Employers Do? Voluntas: International Journal of Voluntary and Nonprofit Organizations, 27(2), 595-617. Just. http://www.jstor.org/stable/43923195

Bang, H., Won, D., \& Kim, Y. (2009). Motivations, commitment, and intentions to continue volunteering for sporting events. Event Management, 13(2), 69 81. https://doi.org/10.3727/ 152599509789686317

BBBSMB (2014). 5 Benefits of volunteering: Four your personal and professional life.

Emassbigs. https://emassbigs.org/5-benefits-of-volunteering-for-your-personal-andpersonal-life/

Booth, J. E., Park, K. W., \& Glomb, T. M. (2009). Employer-supported volunteering benefits: Gift exchange among employers, employees, and volunteer organizations. Human Resource Management, 48(2), 227-249. http://doi.org/10.1002/hrm.20277

Caligiuri, P., Mencin, A., and Jiang, K. (2013). Win-win-win: The influence of company sponsored volunteerism programs on employees, NGOs, and business units. Personnel Psychology, 66, 825ᄀ860. https://doi.org/10.1111/peps.12019

Cepeda-Carrion, Gabriel \& Nitzl, Christian \& Roldán, José. (2018). Mediation Analyses in Partial Least Squares Structural Equation Modeling. Guidelines and Empirical Examples.

Cox, B. (2012). 4 Personal benefits of volunteering in your community. United way. https://www.unitedway.org/blog/4-personal-benefits-of-volunteering-in-your-community\#

Dekkak, M. (2020). The social impact of volunteerism. Dekkak. https://dekkak. com/socialimpact volunteerism/\#: :text=Volunteering\%20improves\%20the $\% \quad 20$ social\% 20associations,organization\%20amongst\%20groups\%20and\% 20neighborhood

DOH all set for 30th SEA Games (2019, December 1). DOH. https://www.doh.gov.ph/dohpress-release/doh-all-set-for-30th-sea-games\#: :text=The $\% 20$ SEA $\% 20$ Games\% 20will\%20gather,and\%20about\%202\%2C800\%20organizing\%20personnel. 
Doherty, A. (2009). The volunteer legacy of a major sport event. Journal of Policy Research in Tourism, Leisure and Events, 1:13, 185207 https://doi.org/10.1080/19407960903204356

Downward, P. \& Ralston, R. (2006). The sports developmental potential of sports event volunteering: Insights from the XVII Manchester Commonwealth Games. European Sport Management Quarterly, 6, 33-351

Fan, Y., Chen, J., Shirkey, G., John, R., Wu, S., Park, H., \& Shao, C. (2016). Application of structural equation modeling (SEM) in ecological studies; an updated review. https://doi.org/10.1186/s13717-016-0063-3

Ford, R., Sturman, Heaton, M. \& Cherill, P. (2012). Total Quality Management for Hospitality and Tourism. Cengage Learning Asia Pte Ltd.

Fornell, C., \& Larcker, D. (1981). Evaluating Structural Equation Models with Unobservable Variables and Measurement Error. Journal of Marketing Research, 18(1), 39-50. https://doi.org/doi:10.2307/3151312

Gagné, M. (2003). The role of autonomy support and autonomy orientation in prosocial behavior engagement. Motivation and Emotion, 27, 199-223

Gavilan, J. (2019, November 26). Venues, budgets, sports: What you need to know about SEA Games 2019. Rappler. https://www.rappler.com/newsbreak/iq/things-to-know-about-seagames-2019

Grant, A. (2012). Giving time, time after time: Work design and sustained employee participation in corporate volunteering. Academy of Management Review. 37. 589-615. 10.5465/amr.2010.0280.

Graves, S. (2019). Understanding volunteer motivation and retention in an art museum. The Florida State University, ProQuest Dissertations Publishing

Goldblatt, J. (2008). Special events. The roots and wings of celebration. John Wiley \& Sons, Inc. pp. xxiii, 5-6, 11, 129-130

Hair, J., Hult, T., Ringle, C., \& Sarstedt, M. (2017). A Primer on Partial Least Squares Structural Equation Modeling (PLS-SEM) 2nd Ed. Sage Publications, Inc.

Hair, J., Hult, T., Ringle, C., \& Sarstedt, M. (2014). A Primer on Partial Least Squares Structural Equation Modeling (PLS-SEM). Sage Publications, Inc.

Harp, E., Scherer, L., and Allen, J., (2017). Volunteer Engagement and retention: Their relationship to community service self-efficacy. Psychology Faculty Publications. 178. https://digitalcommons.unomaha.edu/psychfacpub/178

Hao, Y., Farooq, Q., Zhang Y. (2018). Unattended social wants and corporate social responsibility of leading firms: Relationship of intrinsic motivation of volunteering in proposed welfare programs and employee attributes. Corporate Social Responsibility \& Environmental Management Vol. 25 Issue 6, p1029-1038. 10p. 1 Diagram.https://doi.org/10.1002/csr.1681

Henseler, J., Ringle, C.M. \& Sarstedt, M. (2015). A new criterion for assessing discriminant validity in variance-based structural equation modeling. J. of the Acad. Mark. Sci. 43, 115-135 (2015). https://doi.org/10.1007/s11747-014-0403-8

Informed consent form. (2020). Medicine. https://medicine.hofstra.edu/pdf/research/ sample-informed-consent-form-for-Hofstra-IRB-proposal.pdf 
Inocencio, S. (2019, November 26): 5 things you should know about the biggest edition yet. Asiatatler. https://ph.asiatatler.com/life/2019-sea-games-things-you-should-know-about-thebiggest-edition-yet

Johnson, J., Giannoulakis, C., Felver, N., David, P., \& Scott, B. (2017). Motivation, satisfaction, and retention of sport management student volunteers. Journal of Applied Sport Management; Urbana, 9(1).

Kim, D., Park C., Kim, H., and Kim, J. (2019). Determinants and outcomes of volunteer satisfaction in Mega Sports Events. http://creativecommons.org/licenses/by/4.0/.

Kim, E., Cuskelly G., \& Fredline, L. (2020). Motivational and psychological contract in sport event volunteerism: the impact of contract fulfillment on satisfaction and future behavioral intention. https://doi.org/10.3727/152599519X15506259856110

Kahn, W. A. (1990). Psychological conditions of personal engagement and disengagement at work. Academy of Management Journal, 33, 692-724. https://doi.org/10.2307/256287

Khairullina, V. (2014). Volunteer tourism at sport events, cases: Winter Olympic Games 2014 \& 2014 Ice Hockey Under-18 Championship. Semantic scholar. https://pdfs.semanticscholar. org/913b/132a1a5db21c63ff1fad8c870d3628ef8477.pdf

King, J. \& Cichy, F. (2006). Managing for Quality in the Hospitality Industry. Pearson Prentice Hall

Kock, N. (2020). WarpPLS user manual: Version 7.0. Laredo, TX: ScriptWarp Systems

Kock, N. \& Hadaya. P. (2018). Minimum sample size estimation in PLS-SEM: The inverse square root and gamma-exponential methods. Information Systems Journal, 28(1), 227-261

Lacap, J. (2019). The Mediating Effect of Employee Engagement on the Relationship of Transformational Leadership and Intention to Quit: Evidence from Local Colleges in Pampanga, Philippines. Asia-Pacific Social Science Review. 19. 33-48.

Leng, H. \& Hopfl, H. (2013). Major sporting events and national pride: A comparison between the London 2012 Olympics and Singapore 2010 Youth Olympic Games. https://doi.org/10.1007/978-981-4560-61-0_59

Inquirer.net (2019, November 29). List of venues for 2019 SEA Games. Inquirer. https://sports.inquirer.net/375230/list-venues-for-2019-sea-games

Manalili, T. (2019). Biggest SEA Games in history ends on a high note. PIA. http://pia.gov.ph/features/articles/1031564

Mecbure, A. \& Selen, D. (2020). A theoretical view of extrinsic motivation, intrinsic motivation and performance interaction. Visionary E-Journal / Vizyoner Dergisi. 2020, Vol. 11 Issue 26, p291301. 11p. https://doi.org/10.21076/vizyoner.638479

Miles, J. (2012). Management and organization theory. One Montgomery Street, Suite 1200, Jossey-Bass, A Wiley Imprint

Morales, L. (2019, November 22). 2019 SEA Games by the numbers. Philstar. http://www.philstar.com/sports/2019/11/22/1970688/2019-sea-games-numbers

Murillo, M. (2019, August 26). PHISGOC highlights the key role volunteers play at SEAG. Bworldonline. https://www.bworldonline.com/phisgoc-highlights-key-role-volunteers-play-atseag/

Park, D. B., \& Yoon, Y. S. (2009). Segmentation by motivation in rural tourism: A Korean case study. Tourism Management, 30(1), 99-108. 
Pettinger, T. (2019). Advantages of hosting a major event. Economichelporg. https://www.economicshelporg/blog/4909/economics/advantages-of-hosting-a-major-event/

Philippine Tourism (2020). Tourism demand statistics. DOT. http://www.tourism. gov.ph/Tourismdemand/Arrivals2019.pdf

PHISGOC workforce urged to work hard for SEA Games hosting. (2019, November 10). PNA. https://www.pna.gov.ph/articles/1085581\#: :text=The\%20527\%20members $\% 20$ of\%20the,Sports\%20Hub\%20in\%20Capas\%2C\%20Tarlac.

Rochester, C., Paine, A., Howlett, S., Zimmeck M., \& Ellis, A. (2010). Volunteering and society in the 21st century. Macmillan Publishers Limited, Houndmills. https://doi.org/10.1057/9780230279438

Saul, M. (2020). Maslow's hierarchy of needs. Simply psychology. https://www.simply psychology.org/maslow.html

Schaufeli, W. B., and Bakker, A. B. (2004). Job demands, job resources, and their relationship with burnout and engagement: A multisampling study. Journal Organizational Behavior, 25,293315

SEAP and SEA Games History (2020). Seagfoffice. http://seagfoffice.org/seagf.php? p=sea

Shantz, A., Saksida, T., \& Alfes, K. (2014). Dedicating time to volunteering: Values, engagement, and commitment to beneficiaries. Applied Psychology. An International Review, 63, 671-697

Solberg, H. (2008). Major sporting events: assessing the value of volunteers' work. Managing Leisure. https://doi.org/10.1080/1360671032000075216

Storm, R., \& Jakobsen T. (2019). National pride, sporting success and event hosting: an analysis of intangible effects related to major athletic tournaments. https://doi.org/10.1080/19406940.2019.1646303

Stukas, A., Snyder, M. \& Clary, E. (2016) Understanding and encouraging volunteerism and community involvement. The Journal of Social Psychology, 156:3, 243-255, https://doi.org/10.1080/00224545.2016.1153328

Taber, K.S. (2018). The Use of Cronbach's Alpha When Developing and Reporting Research Instruments in Science Education. Res Sci Educ 48, 1273-1296 (2018). https://doi.org/10.1007/s11165-016-9602-2

Tourism Malaysia (2020). Malaysia tourism statistics. DOT. http://www.tourism gov.my/statistics

Vecina, M. L., Chacón, F., Sueiro, M., \& Barrón, A. (2012). Volunteer engagement: Does engagement predict the degree of satisfaction among new volunteers and the commitment of those who have been active longer? Applied Psychology. An International Review, 61, 130-148

Veludo de Oliveira, T., Pallister, J., \& Foxall, G. (2015). Unselfish: Understanding the role of altruism, empathy and beliefs in volunteering commitment. Journal of Nonprofit \& Public Sector Marketing, 27:4, 373-396 https://doi.org/10.1080/10495142.2015.1080504

Vetitnev, A., Bobina, N., \& Terwiel, F (2019). The influence of host volunteer motivation on satisfaction and attitudes toward Sochi 2014 Olympic Games. https://doi.org/10.3727/152599518X15239930463145 
Walker, J. R. \& Walker, J. T. (2012). Exploring the hospitality industry. Pearson Education, Inc., Prentice-Hall.

Wang, C. \& Yu, L. (2015) Managing student volunteers for mega-events: Motivation and psychological contract as predictors of sustained volunteerism. Asia Pacific Journal of Tourism Research, 20:3, 338-357, https://doi.org/10.1080/10941665.2014.889027

Young, J. (2018). Heroes of employee engagement. Peakon. https://peakon.com/blog/future-work/william-kahn-employee-engagement/

Zalloum, Y. (2011). Social impact of volunteerism. Academia. https://www.academia.edu/34683722/SocialImpactofVolunteerism 